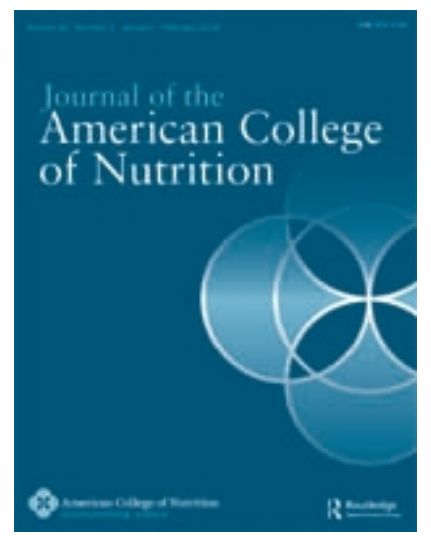

\title{
Acute beetroot juice supplementation does not improve match-play activity in professional tennis players.
}

\begin{tabular}{|c|c|}
\hline Journal: & Journal of the American College of Nutrition \\
\hline Manuscript ID & UACN-2020-0350.R1 \\
\hline Manuscript Type: & Original Research \\
\hline $\begin{array}{r}\text { Date Submitted by the } \\
\text { Author: }\end{array}$ & $n / a$ \\
\hline Complete List of Authors: & $\begin{array}{l}\text { Fernández-Elías, Valentín; European University- Campus Madrid } \\
\text { Courel-Ibañez, Javier; University of Murcia } \\
\text { Pérez-López, Alberto; University of Alcala de Henares } \\
\text { Jodra, Pablo; University of Alcala de Henares } \\
\text { Moreno-Pérez, Victor; Miguel Hernandez University of Elche } \\
\text { Del Coso, Juan; Rey Juan Carlos University } \\
\text { López-Samenes, Álvaro; Francisco de Vitoria University }\end{array}$ \\
\hline Keywords: & $\begin{array}{l}\text { racquet sports, elite athlete, sports performance, nutrition, supplement, } \\
\text { external load }\end{array}$ \\
\hline Abstract: & $\begin{array}{l}\text { Beetroot juice is a source of dietary nitrate (NO3-) recognised as a } \\
\text { potential ergogenic aid to enhance tolerance during endurance exercise } \\
\text { of submaximal-to-maximal intensity. However, little is known about the } \\
\text { effects of beetroot juice on exercise performance in intermittent sports } \\
\text { such as tennis. The present study aimed to determine the effect of acute } \\
\text { beetroot juice supplementation on movement patterns during a } \\
\text { competitive tennis match in professional players. In a double-blind and } \\
\text { randomised experiment, nine professional tennis players performed two } \\
\text { experimental trials } 3 \mathrm{~h} \text { after ingesting either } 70 \mathrm{~mL} \text { of a commercially- } \\
\text { available concentrated beetroot juice }(6.4 \mathrm{mmol} \text { NO3-) or placebo }(0.005 \\
\text { mmol NO3-). In each experimental trial, players completed a } 3-\text { set } \\
\text { tennis match and two performance tests (i.e., serve speed and isometric } \\
\text { handgrip strength) before and after the match. Match-play running } \\
\text { performance was recorded using wearable GPS and accelerometer units. } \\
\text { In comparison to the placebo trial, the acute beetroot juice } \\
\text { supplementation did not modify any match-play running performance } \\
(\mathrm{p}=0.178 \text { to } 0.997, \mathrm{~d}=0.01 \text { to } 0.42) \text {. Furthermore, beetroot juice } \\
\text { supplementation did not alter the pre-to-post match change in serve } \\
\text { speed }(\mathrm{p}=0.663, \mathrm{np} 2=0.03) \text { or isometric handgrip strength }(\mathrm{p}= \\
0.219, \mathrm{np} 2=0.18) \text {. The current results indicated that acute ingestion of }\end{array}$ \\
\hline
\end{tabular}


a commercialised shot of nitrate-rich beetroot juice $(70 \mathrm{~mL}$ containing $6.4 \mathrm{mmol}$ of NO3-) did not produce any performance benefit on tennis match play. Thus, acute beetroot juice supplementation seems an ergogenic aid with little value to enhance physical performance in professional tennis players.

\section{SCHOLARONE \\ Manuscripts}




\section{Acute beetroot juice supplementation does not improve match-play activity in professional tennis}

\section{players}

Valentín E. Fernández-Elias ${ }^{1}$, Javier Courel-Ibañez ${ }^{2}$, Alberto Pérez-Lopez ${ }^{3}$, Pablo Jodra ${ }^{4}$, Victor Moreno-Pérez ${ }^{5}$, Juan Del Coso ${ }^{6}$ and Álvaro López-Samanes ${ }^{7}$.

${ }^{1}$ Universidad Europea de Madrid, Faculty of Sport Sciences, Madrid, Spain.

${ }^{2}$ Faculty of Sport Sciences, University of Murcia, San Javier, Spain.

${ }^{3}$ Department of Biomedical Sciences, Area of Sport and Physical Education, Faculty of Medicine and Health Sciences, University of Alcalá, Madrid, Spain.

${ }^{4}$ Department of Education Sciences, Universidad de Alcalá, Alcalá de Henares, Madrid, Spain.

${ }^{5}$ Center for Translational Research in Physiotherapy, Department of Pathology and Surgery, Universidad Miguel Hernández, San Juan, Spain.

${ }^{6}$ Centre for Sport Studies, Rey Juan Carlos University, Fuenlabrada, Spain.

${ }^{7}$ School of Physiotherapy, Faculty of Health Sciences, Universidad Francisco de Vitoria, Madrid, Spain.

\section{Corresponding author:}

Álvaro López Samanes

School of Physiotherapy, Faculty of Health Sciences, Universidad Francisco de Vitoria Carretera Pozuelo a Majadahonda, Km 1.800, 28223 Pozuelo de Alarcón, Madrid Phone: 34+917091400(Ext.1955); Fax: 34+917091400E-mail: alvaro.lopez@ufv.es 


\begin{abstract}
Beetroot juice is a source of dietary nitrate $\left(\mathrm{NO}_{3}^{-}\right)$recognised as a potential ergogenic aid to enhance tolerance during endurance exercise of submaximal-to-maximal intensity. However, little is known about the effects of beetroot juice on exercise performance in intermittent sports such as tennis. The present study aimed to determine the effect of acute beetroot juice supplementation on movement patterns during a competitive tennis match in professional players. In a double-blind and randomised experiment, nine professional tennis players performed two experimental trials $3 \mathrm{~h}$ after ingesting either $70 \mathrm{~mL}$ of a commercially-available concentrated beetroot juice $\left(6.4 \mathrm{mmol} \mathrm{NO}_{3^{-}}\right)$or placebo $(0.005$ mmol $\mathrm{NO}_{3}$-). In each experimental trial, players completed a 3-set tennis match and two performance tests (i.e., serve speed and isometric handgrip strength) before and after the match. Match-play running performance was recorded using wearable GPS and accelerometer units. In comparison to the placebo trial, the acute beetroot juice supplementation did not modify any match-play running performance ( $p=0.178$ to 0.997 , $d=0.01$ to 0.42 ). Furthermore, beetroot juice supplementation did not alter the pre-topost match change in serve speed $\left(p=0.663, \eta p^{2}=0.03\right)$ or isometric handgrip strength $\left(p=0.219, \eta p^{2}=0.18\right)$. The current results indicated that acute ingestion of a commercialised shot of nitrate-rich beetroot juice ( $70 \mathrm{~mL}$ containing $6.4 \mathrm{mmol}$ of $\mathrm{NO}_{3^{-}}$) did not produce any performance benefit on tennis match play. Thus, acute beetroot juice supplementation seems an ergogenic aid with little value to enhance physical performance in professional tennis players.
\end{abstract}

Keywords: racquet sports, nutrition, external load, supplement, elite athlete, sports performance 


\section{INTRODUCTION}

Beetroot juice is a rich source of dietary inorganic nitrate $\left(\mathrm{NO}_{3^{-}}\right)$which is gaining popularity as a sports nutrition supplement due to its efficacy to enhance several aspects of sports performance. By means of oral administration, the $\mathrm{NO}_{3}$ - contained in beetroot juice can be reduced to nitrite $\left(\mathrm{NO}_{2}^{-}\right)$by xanthine oxidase and by anaerobic bacteria in the oral cavity. Once $\mathrm{NO}_{2}$ - is swallowed, it is instantly decomposed to nitric oxide (NO) in the acidic stomach. (1). Hence, it has been suggested that the intake of dietary $\mathrm{NO}_{3}$ results in an increase of blood levels of $\mathrm{NO}_{3}$ - and $\mathrm{NO}_{2}$ - while they can function as substrates for further generation of bioactive NO (2). The resultant NO is a potent vasodilator compound that increases blood flow in skeletal muscle, enhances muscle oxygenation and improves contractile force in type II (fast-twitch) muscle fibres (3-5). Under this background, the ingestion of beetroot juice and other foods containing high amounts of $\mathrm{NO}_{3}$ - may be used to enhance the endogenous production of $\mathrm{NO}$ through the nitrate-nitrite-NO pathway (6), ultimately affecting exercise performance.

Recent evidence suggests that at least $5 \mathrm{mmol}$ of $\mathrm{NO}_{3}$ - are needed to obtain exercise performance benefits (7). As the average intake of $\mathrm{NO}_{3}$ - in a regular diet is within 1 and 2 mmol per day (8), several companies of dietary supplements have marketed supplements containing higher doses of $\mathrm{NO}_{3}$ - via concentrated beetroot juice or powdered beetroot juice to facilitate the obtaining of this dosage. To this regard, the International Olympic Committee has recently categorised beetroot juice as a dietary supplement with a good level of evidence to enhance endurance performance (9), and, hence, the use of beetroot juice and nitrate-rich dietary supplements has been gaining increasing importance in sport. However, while evidence supports the benefits of beetroot juice supplementation for prolonged submaximal exercise and for high-intensity short-duration 
tasks (i.e., $<15$ min; (7,9)), little is known about the effects of beetroot juice supplementation to improve physical performance in intermittent sports $(10,11)$.

A first study conducted in team-sports players showed that the ingestion of 490 $\mathrm{mL}$ of nitrate-rich beetroot juice $\left(28.7 \mathrm{mmol}\right.$ of $\left.\mathrm{NO}_{3}^{-}\right)$, distributed in seven servings over the $30 \mathrm{~h}$ preceding testing, improved anaerobic capacity with increments of $\sim 4.2 \%$ in the total distance covered in the intermittent Yo-Yo test (12). Likewise, another study found that ingestion of $250 \mathrm{~mL}$ of beetroot juice $\left(\sim 28 \mathrm{mmol}\right.$ of $\mathrm{NO}_{3}$ - in total $)$ during the testing day, $24 \mathrm{~h}$ after and $48 \mathrm{~h}$ after the effort facilitated a more rapid recovery after 100 drop jumps that induced muscle damage (13). Although promising, the acute ingestion of such high doses of beetroot juice could be problematic. According to a recent study, a high portion of the participants consuming $140 \mathrm{~mL}$ of beetroot juice experienced side effects in the hours after ingestion like nausea (41\%), gastrointestinal upset (17\%), beeturia $(17 \%)$ or acid reflux $(8 \% ;(14))$. However, some studies cast doubt on the acute impact of beetroot juice supplementation $(70-140 \mathrm{~mL})$ in common sports-specific high-intensity efforts such as jumps, repeated-sprints or changes of directions (15-19). Furthermore, beetroot juice supplementation $(140 \mathrm{~mL})$ has been found inefficient to improve match play during a basketball competition (17) and to improve physical aspects of tennisspecific performance such as sprint velocity and agility. (16) With this background, it is impossible to objectively determine if acute beetroot juice supplementation with doses that produce a lower rating of side effects may benefit performance.

Although some of the effects of beetroot supplementation found in other investigations, such improved anaerobic capacity (12) and enhanced physical performance in exercise activities shorter than $300 \mathrm{~s}$ (7) may suggest an ergogenic benefit of this type of supplementation on tennis-specific performance, the evidence is scarce and contradictory. Thus, the aim of this double-blind crossover study was to determine 
whether acute supplementation of concentrated beetroot juice (6.4 mmol of $\left.\mathrm{NO}_{3^{-}}\right) 3 \mathrm{~h}$ before a 3-set match would improve the match-play movement patterns in professional tennis players. We hypothesised that this single dose of beetroot juice would be ineffective to modify match-play movement patterns in this sample of highly trained tennis players.

\section{METHODS}

\section{Experimental approach to the problem design}

A randomised, double-blind, placebo-controlled experimental design was used in this study. Participants completed one familiarisation trial and two identical testing sessions in the same outdoor tennis facility, under the same experimental conditions (environmental temperature: $10.6 \pm 4.0^{\circ} \mathrm{C}$ vs $11.4 \pm 2.8^{\circ} \mathrm{C}$ vs and humidity $40 \pm 7 \%$ vs. $32 \pm 5 \%$ for beetroot juice and placebo conditions, respectively) and at the same time in the morning (11.00 h) in order to avoid circadian rhythm effects (20). Participants acted as their own controls to produce a crossover experimental design. In the testing sessions, participants ingested: (a) $70 \mathrm{~mL}$ of concentrated beetroot juice to provide $6.4 \mathrm{mmol}$ of $\mathrm{NO}_{3}$ - or, (b) $70 \mathrm{~mL}$ of a placebo drink with an insignificant amount of $\mathrm{NO}_{3}$ - (i.e., 0.005 mmol of $\mathrm{NO}_{3}^{-}$), as previously reported elsewhere (21). On each testing session, participants ingested the assigned drinks $3 \mathrm{~h}$ before the onset of the trials which consisted of a 3-set tennis match and two tennis-specific tests (i.e., serve speed and isometric handgrip strength) performed before and after the match. During the match, movements patterns were recorded using wearable GPS units and accelerometers. A full familiarisation session was conducted two days before the first testing session. The testing sessions were separated by 1 week to allow a full recovery, testing reproducibility and substance wash out (17). 


\section{Participants}

Eleven professional male tennis players (age: $24.9 \pm 4.2$ years; body mass: $74.4 \pm 8.9 \mathrm{~kg}$; height: $1.82 \pm 0.09 \mathrm{~m}$; tennis experience: $15.4 \pm 6.1$ years; training volume: $11.8 \pm 2.7$ hours per week) were screened and recruited as potential participants. After being fully informed of the experimental protocols, all players gave their informed written consent to participate. Three tennis players were ranked between the $650^{\text {th }}$ and the $1800^{\text {th }}$ place in the Association of Tennis Professionals (ATP) ranking while the remaining eight players were among the 300 best Spanish tennis players. Dietary $\mathrm{NO}_{3}$ - intake was restricted by providing subjects with a list of $\mathrm{NO}_{3}$ - rich foods (e.g., beetroot, celery, or spinach) that they should avoid in the $48 \mathrm{~h}$ before each testing session. Subjects were encouraged to avoid brushing their teeth or using any oral antiseptic rinse, or chewing gum or ingesting sweets that could alter their oral microbiota and interfere with $\mathrm{NO}_{3}$ - reduction during the $24 \mathrm{~h}$ leading up to each experimental trial (22). Subjects were instructed to refrain from any type of exercise or the ingestion of caffeine 24-hours before the experimental trials and to follow a diet sheet consisting of $60 \%$ carbohydrates, $30 \%$ fat, and $10 \%$ proteins. The Bioethics Commission of the Francisco de Vitoria University (number 46/2018) approved the study which complied with the Declaration of Helsinki.

\section{Experimental Protocol}

For all visits, participants arrived at the tennis facilities having consumed the same selfselected breakfast $3 \mathrm{~h}$ before each trial. On each testing day, the tennis players ingested either $70 \mathrm{~mL}$ of concentrated beetroot juice containing $6.4 \mathrm{mmol} \mathrm{NO}_{3^{-}}$(Beet IT; James White Drinks Ltd., Ipswich, UK) or the same amount of a placebo drink (0.005 mmol of $\mathrm{NO}_{3^{-}}$) under the surveillance of researchers. The placebo drink was prepared with $1 \mathrm{~g}$ of powdered beetroot juice (ECO Saludviva, Alicante, Spain) and lemon juice dissolved in water to obtain a drink with similar taste and colour, but with an insignificant amount of 
$\mathrm{NO}_{3}{ }^{-}$, as previously described (21). We administered the treatments $3 \mathrm{~h}$ before the onset of the experimental trials following the results of McIlvenna (23), who found peak plasma concentrations of NO2- $3.5 \mathrm{~h}$ after the intake of beetroot juice. During the following $3 \mathrm{~h}$, participants stayed at the tennis facility resting. Afterwards, a 10-min standardised dynamic warm-up that included running, changes of direction and short sprints, dynamic movements of the shoulder and serves was performed at the beginning of each testing session (24). Serve speed and handgrip strength were measured after the warm-up and these tests were repeated $10 \mathrm{~min}$ after the end of the match to assess pre-post-match changes in these variables. Serve speed was assessed with a sports radar gun (Pocket Radar Ball Coach PR1000BC, Republic of South Korea), positioned on the tennis court in the centre of the baseline, $4 \mathrm{~m}$ behind the server, aligned with the approximate height of ball contact $(\sim 2.2 \mathrm{~m})$ and pointing down the centre of the court $(25)$. For this test, players performed five maximal speed serves with a 20 s rest between them. The speed was only recorded if the ball hit inside a $1 \mathrm{~m} \times 1 \mathrm{~m}$ area allocated in the farther diagonal corner of the serving area (26) to produce a valid serve. The mean velocity of five valid serves was calculated for further analysis. The radar was calibrated at the beginning of each testing session, according to the manufacturer's specifications. After $10 \mathrm{~min}$ of recovery, players completed two maximum isometric voluntary contractions of the dominant hand using a digital handgrip dynamometer (Takei 5101, Tokyo, Japan) with 2 min rest between attempts. Subjects sat with $0^{\circ}$ of shoulder flexion, $0^{\circ}$ of elbow flexion, and the forearm and hand in a neutral position (20) for this measurement. The mean value of these two attempts was recorded for analysis.

\section{Match-play activity}


Ten min after the end of the pre-match testing, players competed in a singles 3-set match against an equally same ranked opponent with a 10-point super-tiebreak, following the rules of the International Tennis Federation. During the experimental trials, the same 2 participants took part in each match to avoid the effects of the opponent's level on the results of the investigation. Matches were officiated by an experienced referee and held on an outdoor tennis court. Players' match activity was monitored using a wearable GPS system (SPI Elite, GPSports Systems, Canberra, Australia) inserted in a purpose-built backpack. Speed and distance were tracked at $15 \mathrm{~Hz}$ and accelerations were recorded at $100 \mathrm{~Hz}$. Players wore the same GPS unit for both matches in order to reduce measurement error. Data collected were analysed using specialised software (TeamAMS, GPSports, Canberra, Australia). Total running distance covered during the match was recorded at five speed thresholds as previously suggested (27): standing and walking $\left(<6.1 \mathrm{~km} \cdot \mathrm{h}^{-1}\right)$, jogging (from 6.1 to $12.0 \mathrm{~km} \cdot \mathrm{h}^{-1}$ ), cruising (from 12.1 to $14.0 \mathrm{~km} \cdot \mathrm{h}^{-1}$ ), striding (from 14.1 to $\left.18.0 \mathrm{~km} \cdot \mathrm{h}^{-1}\right)$ and high-intensity running $\left(>18.1 \mathrm{~km} \cdot \mathrm{h}^{-1}\right)$. Peak running velocity, the number of high intensity accelerations (i.e., $>1.5 \mathrm{~m} \cdot \mathrm{s}^{-2}$ ) and decelerations (i.e., $<-1.5$ $\mathrm{m} \cdot \mathrm{s}^{-2}$ ) and the number of body impacts were collected. Due to the different match durations, all variables analysed were relativised per minute of match duration The rating of perceived exertion (RPE) was obtained 30 min after of the end of the match with a 10point scale (28).

\section{Statistical analysis}

The required sample size was determined by statistical power calculation (29) on the basis of previous studies that described the variability on the distance covered at $>18 \mathrm{~km} / \mathrm{h}$ in tennis players (30) and determined the effects of BR on match-play movement patterns in basketball (17). Ten subjects would be required to detect changes of $0.61 \pm 0.50 \mathrm{~m} \cdot \mathrm{min}^{-}$ 
1 in the distance covered at $>18 \mathrm{~km} \cdot \mathrm{h}^{-1}$, with a power of 0.80 and two-tailed $\alpha$ level set at 0.05 . Data are presented as mean \pm standard deviation (SD). The Shapiro-Wilks test revealed that data were normally distributed. Paired $t$-tests were performed to compare match-play running performance between beetroot juice and placebo trials. Two-way (treatment $\mathrm{x}$ time) repeated measures analysis of variance (ANOVA) was used to identify differences in the two tennis-specific tests performed before and after the match. Following a significant $F$ test in the ANOVA (Greenhouse-Geisser correction for the assumption of sphericity), differences between means were identified using the Bonferroni post hoc procedure. Statistical significance was set at $p<0.05$. Cohen's $d$ ( $\pm 95 \%$ confidence intervals) for $t$-tests, and partial eta squared $\left(\eta p^{2}\right)$ for ANOVA were calculated to estimate the effect size (31). Calculations were made using SPSS software (v. 24, IBM, Armonk, NY, USA). MedCalc (v. 18.2.1, MedCalc Software bvba, Ostend, Belgium) was used for sample size and power calculations.

\section{RESULTS}

Two participants were unable to complete the second testing session and therefore data from the nine participants who completed the experiment were considered for the analysis. The order of the trials was identified by $56 \%$ of the participants $(5 / 9$ participants). The nutritional strategy was well tolerated without severe adverse effects, with only one player showing gastrointestinal discomfort after the placebo ingestion. ANOVA revealed no main effect of the treatment $\left(p=0.227 ; \eta p^{2}=0.15\right)$ or time $(p=$ $\left.0.117 ; \eta p^{2}=0.28\right)$ or treatment $\mathrm{x}$ time interaction $\left(p=0.663 ; \eta p^{2}=0.03\right)$ on serve speed. Similarly, ANOVA revealed no main effect of the treatment $\left(p=0.152 ; \eta p^{2}=0.24\right)$ or time $\left(p=0.711 ; \eta p^{2}=0.02\right)$ or treatment $\mathrm{x}$ time interaction $\left(p=0.219 ; \eta p^{2}=0.18\right)$ on handgrip strength (Figure 1). 


\section{$* * *$ Figure 1 about here $* * *$}

The duration of the matches was similar with beetroot juice and with the placebo $(72.5 \pm$ 20.3 vs. $76.6 \pm 12.0 \mathrm{~min}, p=0.703)$. Tennis match-play running performance is presented in Table 1. There were no between-treatment differences in any of the variables recorded during the match while the magnitude of the effect sizes was small (Figure 2). The RPE after the match was similar with beetroot juice and with the placebo $(5.3 \pm 2.3$ vs. $5.0 \pm$ $2.6, p=0.551)$.

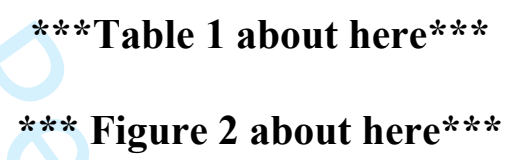

\section{DISCUSSION}

In this double-blind, placebo-controlled crossover study, the acute ingestion of a commercialised shot of nitrate-rich beetroot juice ( $70 \mathrm{~mL}$ containing $6.4 \mathrm{mmol}$ of $\mathrm{NO}_{3^{-}}$) was ineffective to improve match-play running performance and pre-to-post-match serve speed and handgrip strength changes in professional tennis players. Furthermore, the ingestion of beetroot juice did not modify the rating of perceived exertion after the match. These results are in line with previous studies reporting no impact of acute beetroot juice ingestion on jumping capacity, velocity in short distances and on the ability to changeof-direction $(16,17)$ because the current protocol of beetroot supplementation was ineffective to produce ergogenic benefits on tennis-specific performance. Overall, the current investigation contributes to existing knowledge by providing new evidence on the lack of influence of beetroot juice on match-play performance in professional tennis players. 
One previous study in highly-trained tennis players found no effects on neuromuscular performance variables of consuming $70 \mathrm{~mL}$ of concentrated beetroot juice (16). In addition, a recent systematic review indicates that approximately $68 \%$ of the investigations geared to determine the effect of $\mathrm{NO}_{3}$ - supplementation do not observe an ergogenic effect on exercise performance (7). In this regard, it seems that beetroot juice supplementation is less effective in in participants with excellent aerobic capacity $(7,32)$, likely due to high endogenous production of NO and enhanced blood flow to exercising muscles induced by training. The lack of performance benefits of acute beetroot juice supplementation in this sample of professional tennis players reinforces the idea that this supplement may be ineffective to increase the physical and physiological aspects related to elite tennis performance. Certainly, higher doses $(12,13)$ or chronic beetroot juice supplementation (33-36) may be required to obtain the potential benefits of this dietary supplement for exercise performance in intermittent efforts. However, the ingestion of beetroot juice at higher doses than the one used in this investigation may cause some gastrointestinal side effects (14). According to our findings, a commercialised shot of nitrate-rich beetroot juice produced no extra benefits during a 60-80 min tennis competition in professional tennis players. Nonetheless, these data do not dispute the well-established effect that beetroot juice and other nitrate-rich supplements have to enhance endurance performance during prolonged, low intensity and high volume exercise in recreational athletes $(9,21)$.

The current experiment is innovative because it provides new evidence about the effect of beetroot juice supplementation on tennis match play running patterns. GPS tracking technology is a useful tool to quantify the running external load during a match as it is capable of recording the distance covered at customized speed thresholds during real and simulated sports competition $(37,38)$. The research measuring the effectiveness 
of beetroot juice supplementation in in-game performance through GPS technology is scarce, despite utility of this methodology to assess the effect of nutritional treatments on sports performance (39). One recent study conducted on young basketball players (17) found no improvements from acute beetroot ingestion in match activity, measured with GPS. In addition, the current investigation helps to establish that acute beetroot juice supplementation with a commercialised shot of nitrate-rich beetroot juice $(70 \mathrm{~mL}$ containing $6.4 \mathrm{mmol}$ of $\mathrm{NO}_{3^{-}}$) has little benefit to enhance physical performance during simulated tennis match play. From a practical perspective, higher doses of up to $28 \mathrm{mmol}$ of $\mathrm{NO}_{3}$ - may be necessary to obtain a potential ergogenic effect in intermittent-based sports $(12,13)$.

The role of beetroot juice supplementation in accelerating recovery after exercise has been previously addressed with positive results after chronic administration $(34,36)$. In soccer players, $140 \mathrm{~mL}$ of beetroot juice twice per day for 7 days reduced post exercise perceived muscle soreness and improved the recovery of muscle function after a match. Furthermore, chronic beetroot juice administration with higher doses $(\sim 12 \mathrm{mmol}$ during 7 days) was found effective in preventing handgrip strength decline in response to exercise in jiu-jitsu athletes (34). In our study, we sought to identifying the influence of an acute administration of $70 \mathrm{~mL}$ of beetroot juice on mitigating the competition-induced fatigue in serve speed and handgrip strength. The tennis serve is a repetitive, highintensity stroke which combines velocity and accuracy to hit the ball as fast as possible towards the planned target (40). Although maintaining serve speed and accuracy during the game is likely to increase the winning options (41), ball speed may be influenced by competition-induced fatigue (42). Likewise, loss in handgrip strength may negatively affect service performance (43). In this sense, our results suggested no benefits of acute beetroot juice supplementation in mitigating fatigue after a 3-set tennis competition at a 
professional level. This lack of effect may be accounted for by the game settings and duration (60-80 min). While these matches are commonly played as a training task, longer and higher-demanding games are expected during professional tennis competitions. The current data indicate that acute ingestion of beetroot juice was not effective to enhance the maintenance of muscle performance during a tennis match. Still, it remains the possibility of obtaining some benefits during the recovery process of exercise when the protocol of beetroot juice supplementation is maintained for several days $(34,36)$.

Aside from its strengths, the current investigation has several limitations that should be discussed to enhance is applicability to real sports contexts. First, we did not obtain blood samples and thus, we were unable to assess the levels of circulating $\mathrm{NO}_{3}$ and $\mathrm{NO}_{2}$ - after beetroot juice administration. Second, we selected a dose of $6.4 \mathrm{mmol}$ of $\mathrm{NO}_{3}$ - in the experimental trial with concentrated beetroot juice which is above the threshold suggested to obtain ergogenic benefits $(7,21,44)$. Thus, despite the current protocol of beetroot juice supplementation has been confirmed by other researchers to be effective to enhance physical performance, the inclusion of blood samples would have helped in determining the actual levels of $\mathrm{NO}_{3}$ - elicited by the supplementation protocol before and after the tennis match. Third, the lack of performance-enhancing benefits of beetroot juice supplementation may be affected by the limited sample size and the moderate physical demands of the tennis matches. Despite the duration of the matches was longer than $70 \mathrm{~min}$ in both protocols and participants were encouraged to produce their highest performance during the matches, these professional tennis players are accustomed to high levels of training and longer competitive matches which might explain their moderate ratings of perceived exertion after the testing protocols. Furthermore, this sample of professional tennis players potentially have high levels of central and local training-induced adaptations. As the effectiveness of beetroot juice 
supplementation may vary depending on the fitness level of the individual (7), the outcomes of this investigation should be only translated to elite male tennis players unhabituated to beetroot ingestion. Hence, the possibility still remains that acute beetroot supplementation in the dose used in this investigation produces some performance benefits in tennis matches that are longer and more exhausting than the ones investigated here, or in tournaments where two matches are played on the same day. However, these speculations need further exploration in subsequent studies.

In conclusion, acute ingestion of a commercialised shot of concentrated beetroot juice ( $70 \mathrm{~mL}$ containing $6.4 \mathrm{mmol}$ of $\mathrm{NO}_{3}$-) was ineffective to increase tennis match-play running performance in professional players. Moreover, the acute ingestion of concentrated beetroot juice had no impact on strength changes induced by the match. These outcomes suggest that acute nitrate-rich beetroot juice supplementation seems an ergogenic aid with little value to enhance physical performance in professional tennis players. Future investigations are required to corroborate these findings in longer matches and clarify the potential benefits of beetroot juice on other aspects of tennis performance. 


\section{ACKNOWLEDGMENTS}

The authors wish to thank the tennis players for their invaluable contribution to the study.

\section{FINANCIAL DISCLOSURE}

This study was partially funded by the Universidad Francisco de Vitoria and Banco

Santander via grants (UFV-2020/44).

\section{CONFLICT OF INTEREST}

The authors declare no support from any organisation for the submitted work; no financial relationships with any organisations that might have an interest in the submitted work in the previous 3 years; and no other relationships or activities that could appear to have influenced the submitted work. 


\section{REFERENCES}

1. Ashworth A, Cutler C, Farnham G, Liddle L, Burleigh M, Rodiles A, et al. Dietary intake of inorganic nitrate in vegetarians and omnivores and its impact on blood pressure, resting metabolic rate and the oral microbiome. Free Radic Biol Med. 2019;138:63-72.

2. Jones AM. Dietary Nitrate Supplementation and Exercise Performance. Sport Med. 2014; 44:35-45.

3. Papadopoulos S, Dipla K, Triantafyllou A, Nikolaidis MG, Kyparos A, Touplikioti P, et al. Beetroot Increases Muscle Performance and Oxygenation During Sustained Isometric Exercise, but Does Not Alter Muscle Oxidative Efficiency and Microvascular Reactivity at Rest. J Am Coll Nutr. 2018 2020;37(5):361-72.

4. Jones AM, Thompson C, Wylie LJ, Vanhatalo A. Dietary Nitrate and Physical Performance. Annu Rev Nutr. 2018;38(1):303-28.

5. Whitfield J, Ludzki A, Heigenhauser GJF, Senden JMG, Verdijk LB, van Loon LJC, et al. Beetroot juice supplementation reduces whole body oxygen consumption but does not improve indices of mitochondrial efficiency in human skeletal muscle. J Physiol 2016;594(2):421-35.

6. Lundberg JO, Weitzberg E, Gladwin MT. The nitrate-nitrite-nitric oxide pathway in physiology and therapeutics. Nat Rev Drug Discov. 2008;7(2):156-67.

7. Senefeld JW, Wiggins CC, Regimbal RJ, Dominelli PB, Baker SE, Joyner MJ. Ergogenic Effect of Nitrate Supplementation: a Systematic Review and Metaanalysis. Med Sci Sport Exerc. 2020;52(10):2250-61.

8. Bryan NS. Food, nutrition, and the nitric oxide pathway: biochemistry and bioactivity [Internet]. 2010 [cited 2020 Sep 21]. 218 p. Available from: https://www.destechpub.com/product/food-nutrition-and-the-nitric-oxidepathway/

9. Maughan RJ, Burke LM, Dvorak J, Larson-Meyer DE, Peeling P, Phillips SM, et al. IOC consensus statement: Dietary supplements and the high-performance athlete. Br J Sports Med. 2018;52(7):439-55.

10. Domínguez R, Maté-Muñoz JL, Cuenca E, García-Fernández P, Mata-Ordoñez F, Lozano-Estevan MC, et al. Effects of beetroot juice supplementation on intermittent high-intensity exercise efforts. J Int Soc Sports Nutr. 2018;15(2):116. 
11. Pawlak-Chaouch M, Boissière J, Munyaneza D, Gamelin F-X, Cuvelier G, Berthoin S, et al. Beetroot Juice Does Not Enhance Supramaximal Intermittent Exercise Performance in Elite Endurance Athletes. J Am Coll Nutr. 2019;38(8):729-38.

12. Wylie LJ, Mohr M, Krustrup P, Jackman SR, Ermıdis G, Kelly J, et al. Dietary nitrate supplementation improves team sport-specific intense intermittent exercise performance. Eur J Appl Physiol. 2013;113(7):1673-84.

13. Clifford T, Bell O, West DJ, Howatson G, Stevenson EJ. The effects of beetroot juice supplementation on indices of muscle damage following eccentric exercise. Eur J Appl Physiol. 2016;116(2):353-62.

14. Wickham KA, McCarthy DG, Pereira JM, Cervone DT, Verdijk LB, van Loon LJC, et al. No effect of beetroot juice supplementation on exercise economy and performance in recreationally active females despite increased torque production. Physiol Rep. 2019;7(2):e13982.

15. Cuenca E, Jodra P, Pérez-López A, González-Rodríguez L, Fernandes da Silva S, Veiga-Herreros P, et al. Effects of Beetroot Juice Supplementation on Performance and Fatigue in a 30-s All-Out Sprint Exercise: A Randomized, Double-Blind Cross-Over Study. Nutrients. 2018;10(9):1222.

16. López-Samanes Á, Pérez-López A, Moreno-Pérez V, Nakamura FY, AcebesSánchez J, Quintana-Milla I, et al. Effects of beetroot juice ingestion on physical performance in highly competitive tennis players. Nutrients. 2020;12(2):1-10.

17. López-Samanes Á, Parra AG, Moreno-Pérez V, Courel-Ibáñez J. Does acute beetroot juice supplementation improve neuromuscular performance and match activity in young basketball players? A randomized, placebo- controlled study. Nutrients. 2020;12(1):188.

18. Martin K, Smee D, Thompson KG, Rattray B. No Improvement of RepeatedSprint Performance With Dietary Nitrate. Int J Sports Physiol Perform. 2014;9(5):845-50.

19. Reynolds CME, Halpenny C, Hughes C, Jordan S, Quinn A, Egan B. Acute ingestion of beetroot juice does not improve repeated sprint performance in male team sport athletes. J Sports Sci. 2020;

20. López-Samanes Á, Moreno-Pérez D, Maté-Muñoz JL, Domínguez R, Pallarés JG, Mora-Rodriguez R, et al. Circadian rhythm effect on physical tennis performance in trained male players. J Sports Sci. 2017;35(21):2121-8. 
21. Domínguez R, Garnacho-Castaño MV, Cuenca E, García-Fernández P, MuñozGonzález A, de Jesús F, et al. Effects of beetroot juice supplementation on a 30-s high-intensity inertial cycle ergometer test. Nutrients. 2017;9(12):1360.

22. Bescos R, Ashworth A, Cutler C, Brookes ZL, Belfield L, Rodiles A, et al. Effects of Chlorhexidine mouthwash on the oral microbiome. Sci Rep. 2020;10(1):5254.

23. McIlvenna LC, Monaghan C, Liddle L, Fernandez BO, Feelisch M, Muggeridge DJ, et al. Beetroot juice versus chard gel: A pharmacokinetic and pharmacodynamic comparison of nitrate bioavailability. Nitric Oxide - Biol Chem [Internet]. 2017; 64:61-7.

24. Ayala F, Moreno-Pérez V, Vera-Garcia FJ, Moya M, Sanz-Rivas D, FernandezFernandez J. Acute and Time-Course Effects of Traditional and Dynamic WarmUp Routines in Young Elite Junior Tennis Players. PLoS One. 2016;11(4):e0152790.

25. Moreno-Pérez V, López-Samanes Á, Domínguez R, Fernández-Elías VE, González-Frutos P, Fernández-Ruiz V, et al. Acute effects of a single tennis match on passive shoulder rotation range of motion, isometric strength and serve speed in professional tennis players. PLoS One. 2019;14(4):e0215015.

26. Gescheit DT, Cormack SJ, Reid M, Duffield R. Consecutive days of prolonged tennis match play: Performance, physical, and perceptual responses in trained players. Int J Sports Physiol Perform. 2015;10(7):913-20.

27. Gallo-Salazar C, Areces F, Abián-Vicén J, Lara B, Salinero JJ, Gonzalez-Millán $\mathrm{C}$, et al. Enhancing physical performance in elite junior tennis players with a caffeinated energy drink. Int J Sports Physiol Perform. 2015;10(3):305-10.

28. Foster C, Florhaug JA, Franklin J, Gottschall L, Hrovatin LA, Parker S, et al. A new approach to monitoring exercise training. J Strength Cond Res. 2001;15(1):109-15.

29. Vincent WJ. Statistics in kinesiology. Vol. 10. John Wiley \& Sons; 2005.

30. Gallo-Salazar C, Del Coso J, Sanz-Rivas D, Fernandez-Fernandez J. Game Activity and Physiological Responses of Young Tennis Players in a Competition With 2 Consecutive Matches in a Day. Int J Sports Physiol Perform. 2018;14(7):887-93.

31. Lakens D. Calculating and reporting effect sizes to facilitate cumulative science: A practical primer for t-tests and ANOVAs. Front Psychol. 2013;4:863. 
32. Olsson H, Al-Saadi J, Oehler D, Pergolizzi J, Magnusson P. Physiological Effects of Beetroot in Athletes and Patients. Cureus. 2019;11(12):e6355.

33. Nyakayiru J, Jonvik KL, Trommelen J, Pinckaers PJM, Senden JM, van Loon LJC, et al. Beetroot Juice Supplementation Improves High-Intensity Intermittent Type Exercise Performance in Trained Soccer Players. Nutrients. 2017;9(3):314.

34. de Oliveira GV, Alvares TS, do Nascimento LAD, Volino-Souza M, Mesquita J de S. Beetroot-based gel supplementation improves handgrip strength and forearm muscle $\mathrm{O} 2$ saturation but not exercise tolerance and blood volume in jiujitsu athletes. Appl Physiol Nutr Metab. 2018;43(9):920-7.

35. Thompson C, Vanhatalo A, Jell H, Fulford J, Carter J, Nyman L, et al. Dietary nitrate supplementation improves sprint and high-intensity intermittent running performance. Nitric Oxide - Biol Chem. 2016;61:55-61.

36. Daab W, Bouzid MA, Lajri M, Bouchiba M, Saafi MA, Rebai H. Chronic Beetroot Juice Supplementation Accelerates Recovery Kinetics following Simulated Match Play in Soccer Players. J Am Coll Nutr. 2020;3:1-9.

37. Cardinale M, Varley MC. Wearable training-monitoring technology: Applications, challenges, and opportunities. Int J Sports Physiol Perform. 2017;12(Suppl 2):55-62.

38. Vanrenterghem J, Nedergaard NJ, Robinson MA, Drust B. Training Load Monitoring in Team Sports: A Novel Framework Separating Physiological and Biomechanical Load-Adaptation Pathways. Sport Med. 2017;47(11):2135-42.

39. Aughey RJ. Applications of GPS Technologies to Field Sports. Int J Sports Physiol Perform. 2011; 6(3):295-310.

40. Myers NL, Sciascia AD, Westgate PM, Kibler WB, Uhl TL. Increasing Ball Velocity in the Overhead Athlete: A Meta-analysis of Randomized Controlled Trials. J Strength Cond Res. 2015;29(10):2964-79.

41. O’Donoghue GP, Brown E. The Importance of Service in Grand Slam Singles Tennis. Int J Perform Anal Sport. 2008;8(3):70-8.

42. Martin C, Kulpa R, Ezanno F, Delamarche P, Bideau B. Influence of Playing a Prolonged Tennis Match on Shoulder Internal Range of Motion. Am J Sports Med. 2016;44(8):2147-51.

43. Baiget E, Corbi F, Fuentes JP, Fernández-Fernández J. The Relationship between Maximum Isometric Strength and Ball Velocity in the Tennis Serve. J Hum Kinet. 2016;53(1):63-71. 
44. Muggeridge DJ, Howe CCF, Spendiff O, Pedlar C, James PE, Easton C. The effects of a single dose of concentrated beetroot juice on performance in trained flatwater kayakers. Int J Sport Nutr Exerc Metab. 2013;23(5):498-506. 
Figure 1. Serve speed and handgrip strength before and after a 3-set tennis match with the ingestion of $70 \mathrm{~mL}$ of beetroot juice $\left(6.4 \mathrm{mmol} \mathrm{NO}_{3^{-}}\right)$or a placebo in professional tennis players.

The bars represent the mean value for nine professional tennis players before and after the match for each treatment and the lines represent individual responses.

Figure 2. Effect sizes ( $\pm 95 \%$ confidence intervals) for movement patterns during a 3 -set tennis match with the ingestion of $70 \mathrm{~mL}$ of beetroot juice $\left(6.4 \mathrm{mmol} \mathrm{NO}_{3^{-}}\right)$or a placebo in professional tennis players. 
Table 1. Tennis match-play demands after the ingestion of $70 \mathrm{~mL}$ of beetroot juice $(6.4$ mmol $\left.\mathrm{NO}_{3^{-}}\right)$or placebo $\left(0.4 \mathrm{mmol} \mathrm{NO}_{3^{-}}\right)$in professional tennis players. Data presented as Mean $\pm \mathrm{SD}$.

\begin{tabular}{cccc}
\hline GPS-derived variables & Placebo & Beetroot juice & $\boldsymbol{p}$ \\
\hline Peak velocity $\left(\mathrm{km} \cdot \mathrm{h}^{-1}\right)$ & $19.8 \pm 2.5$ & $19.9 \pm 2.7$ & 0.929 \\
Total distance covered $\left(\mathrm{m} \cdot \mathrm{min}^{-1}\right)$ & $48.2 \pm 20.2$ & $46.4 \pm 25.3$ & 0.891 \\
$<6.1 \mathrm{~km} \cdot \mathrm{h}^{-1}\left(\mathrm{~m} \cdot \mathrm{min}^{-1}\right)$ & $38.2 \pm 15.6$ & $35.4 \pm 17.4$ & 0.782 \\
6.1 to $12.0 \mathrm{~km} \cdot \mathrm{h}^{-1}\left(\mathrm{~m} \cdot \mathrm{min}^{-1}\right)$ & $8.4 \pm 4.3$ & $9.2 \pm 6.3$ & 0.780 \\
12.1 to $14.0 \mathrm{~km} \cdot \mathrm{h}^{-1}\left(\mathrm{~m} \cdot \mathrm{min}^{-1}\right)$ & $0.84 \pm 0.46$ & $0.90 \pm 0.85$ & 0.873 \\
14.1 to $18.0 \mathrm{~km} \cdot \mathrm{h}^{-1}\left(\mathrm{~m} \cdot \mathrm{min}^{-1}\right)$ & $0.70 \pm 0.48$ & $0.73 \pm 0.81$ & 0.924 \\
$>18 \mathrm{~km} \cdot \mathrm{h}^{-1}\left(\mathrm{~m} \cdot \mathrm{min}{ }^{-1}\right)$ & $0.12 \pm 0.11$ & $0.19 \pm 0.21$ & 0.178 \\
Number of accelerations $\left(>1.5 \mathrm{~m} \cdot \mathrm{s}^{-1}\right)$ & $18.2 \pm 11.1$ & $18.0 \pm 13.4$ & 0.950 \\
Number of decelerations $\left(<-1.5 \mathrm{~m} \cdot \mathrm{s}^{-1}\right)$ & $19.1 \pm 9.9$ & $20.7 \pm 13.6$ & 0.736 \\
Total Impacts $\left(\mathrm{number} \cdot \mathrm{min}^{-1}\right)$ & $33.5 \pm 16.9$ & $32.2 \pm 18.5$ & 0.898 \\
\hline
\end{tabular}




\section{A) Serve speed test}
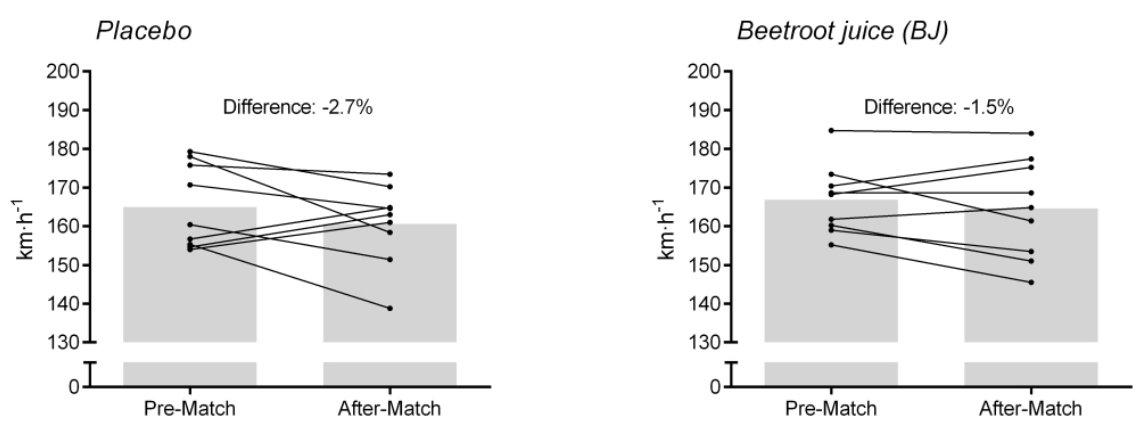

\section{B) Handgrip strength test}
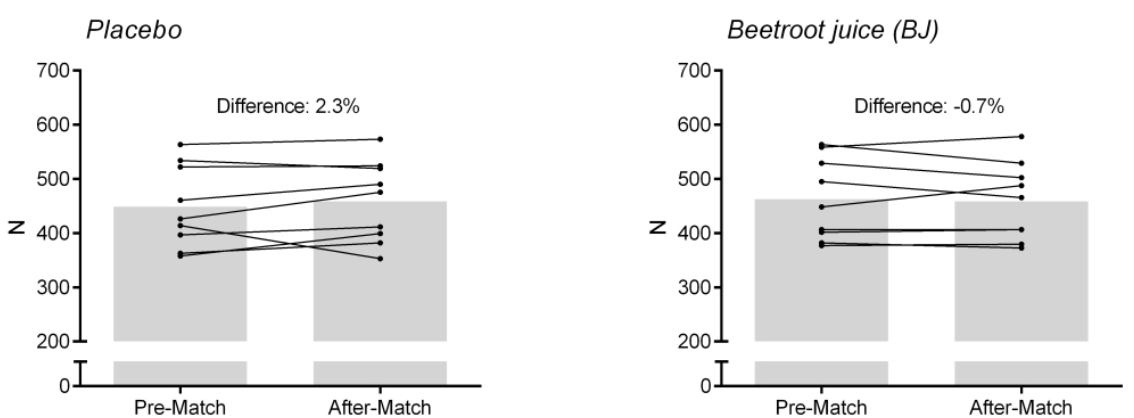

Serve speed and handgrip strength before and after a 3-set tennis match with the ingestion of $70 \mathrm{~mL}$ of beetroot juice (6.4 mmol NO3-) or a placebo in professional tennis players.

$196 \times 157 \mathrm{~mm}(600 \times 600 \mathrm{DPI})$ 


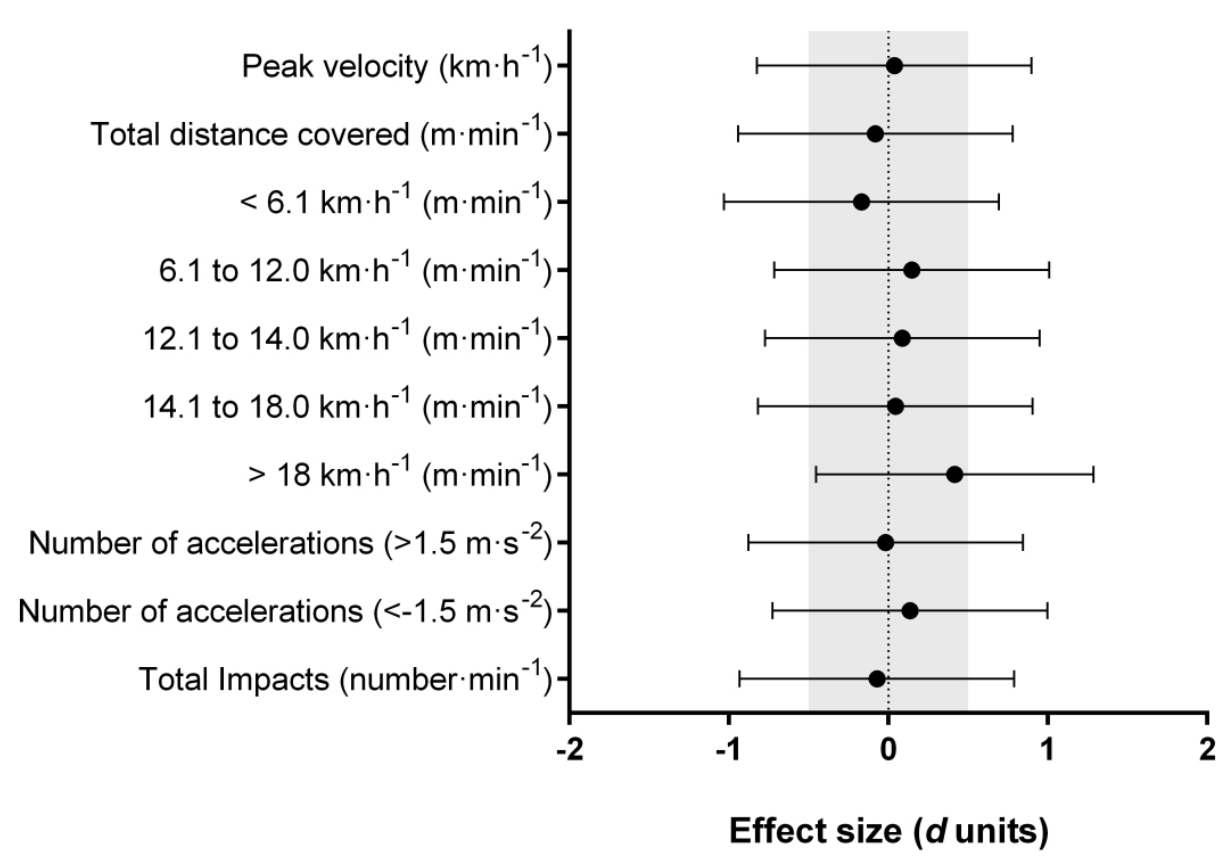

Effect sizes ( $\pm 95 \%$ confidence intervals) for movement patterns during a 3-set tennis match with the ingestion of $70 \mathrm{~mL}$ of beetroot juice $(6.4 \mathrm{mmol} \mathrm{NO3-})$ or a placebo in professional tennis players.

$155 \times 108 \mathrm{~mm}(600 \times 600 \mathrm{DPI})$ 